\title{
Hemodata: um aplicativo para gerenciamento em bancos de sangue
}

\author{
Ebenézer Holz Nogueira de Carvalho ${ }^{1}$, Waldeyr Mendes Cordeiro da Silva ${ }^{1}$ \\ ${ }^{1}$ Instituto Federal de Educação, Ciência e Tecnologia de Goiás (IFG) \\ CEP: 73.813-816, Rua 64 Parque Lago - Formosa - GO - Brasil \\ ebenezerholz710@gmail.com, waldeyr.mendes@ifg.edu.br
}

\begin{abstract}
A blood center is a specialized place dedicated to collecting, processing, and preparing blood whose purpose is to provide hemotherapeutic and hematological assistance to support the health system. Often in blood centers, notably those located in small municipalities, the management of blood bags takes place manually through notebooks. Such a procedure makes managing blood bags vulnerable to failure. Therefore, the Hemodata mobile app's goal is to manage blood bags in a law's adherent way, assisting in the administrative tasks of health agents. Exploring the advantages of a mobile application, Hemodata allows us to register blood bags identified by bar codes and maintain an updated historical record throughout its life cycle.
\end{abstract}

Resumo. Hemocentros são locais especializados que dedicam-se à coleta, ao processamento, e à preparação do sangue, cuja finalidade é prestar assistência e apoio hemoterápico e hematológico aos serviços de saúde. Frequentemente nos hemocentros, notadamente naqueles localizados em pequenos municípios, o gerenciamento das bolsas de sangue ocorre de forma manual, por meio de cadernos, tornando a tarefa de gerenciamento de bolsas de sangue vulnerável a falhas. O objetivo do aplicativo móvel Hemodata, é portanto, gerenciar bolsas de sangue em hemocentros de forma aderente à legislação vigente, auxiliando nas tarefas administrativas dos agentes de saúde. Explorando as vantagens de um aplicativo móvel, o Hemodata permite manter o registro de bolsas de sangue, identificadas por meio de códigos de barras com histórico atualizado em todo o seu ciclo de vida.

\section{Introdução}

No Brasil, a Lei $n^{\circ} 10.205$, de 21 de Março de 2001 regulamenta o $§ 4^{\circ}$ do art. 199 da Constituição e trata sobre a execução da coleta, processamento, estocagem, distribuição e aplicação do sangue, seus componentes e derivados e estabelece o ordenamento institucional indispensável à execução adequada dessas atividades [BRASIL 2001a]. Outras normas complementares, incluem a Portaria de no 158 do Ministério de Saúde [BRASIL 2016] e a Lei $\mathrm{n}^{\circ}$ 7.649, de 25 de janeiro de 1988 [BRASIL 1988]. Nesse contexto regulatório, os hemocentros figuram como locais especializados em coletar, processar, preparar e armazenar sangue humano com a finalidade de prestar assistência e apoio hemoterápico e hematológico à rede de serviços de saúde [BRASIL 2001b].

Em geral, os aplicativos para hemocentros disponíveis para smartphones estão relacionados à captação de doadores e agendamento de doações em hemocentros cadas- 
trados. Apesar de promover interatividade, mobilização e engajamento social, esses aplicativos não apoiam as rotinas dos hemocentros. Este trabalho apresenta uma protótipo de solução baseada em um aplicativo mobile (Android e iOS) para gerenciamento de bolsas de sangue em hemocentros, o Hemodata.

\section{Hemodata}

O aplicativo Hemodata é atualmente um Produto Minimamente Viável (MVP) com capacidade para gerenciar de bolsas de sangue em hemocentros na forma da legislação vigente, especialmente a Portaria ${ }^{\circ} 158$, de 4 de fevereiro de 2016 [BRASIL 2016]. É possível adicionar um técnico no sistema a partir de dados como seu Nome, E-mail, CPF e função.

O cadastro de bolsas de sangue utiliza um leitor de código de barras baseado na câmera do smartphone, minimizando a exposição da bolsa ao ambiente externo, que é fator de risco para o sangue coletado. Os dados de uma bolsa de sangue cadastrada incluem "Tipo de bolsa", "Tipo sanguíneo", "Rh", o "Código de barras", "Data e hora" do cadastro, a "Data validade" baseada na data e hora do cadastro, o "E-mail" e o "CPF" do técnico responsável pelo cadastro, e um status inicial ("Não Liberado") da bolsa de sangue. Durante o ciclo de vida da bolsa de sangue no Hemodata, seu status é atualizado todas as ações executadas são registradas, incluindo a data, a hora e os dados do próprio técnico executor da ação. Os status possíveis para a bolsa são: "Não Liberado", "Transfundida", "Expurgada" ou "Expirada". Algumas mudanças de status requerem ação do técnico, enquanto outras são automáticas, como expiração após prazo de validade. O Hemodata oferece um relatório gráfico, onde é possível visualizar os níveis de estoques dos diferentes tipos

de bolsas

de sangue.

O Hemodata (Figura 1) é um aplicativo capaz de gerenciar bolsas de sangue em hemocentros de forma aderente à legislação em vigor, gerando informações confiáveis sobre o banco de sangue local. Para além de um aplicativo, o Hemodata é uma contribuição cidadã que colabora para a eficiência da coleta, armazenamento e utilização de bolsas de sangue, serviço essencial para a área de saúde.

\section{Referências}

BRASIL (1988). Lei N $\mathrm{N}^{\circ} 7.649$, de 25 de Janeiro de 1988. Presidência da República Casa Civil.

BRASIL (2001a). Lei No 10.205, de 21 DE Março de 2001. Presidência da República Casa Civil.

BRASIL (2001b). Resolução ANVISA no 151 de 21 de Agosto de 2001. ANVISA.

BRASIL (2016). Portaria $n^{\circ} 158$, de 4 de Fevereiro de 2016regulamento técnico de procedimentos hemoterápicos . Ministério da Saúde.

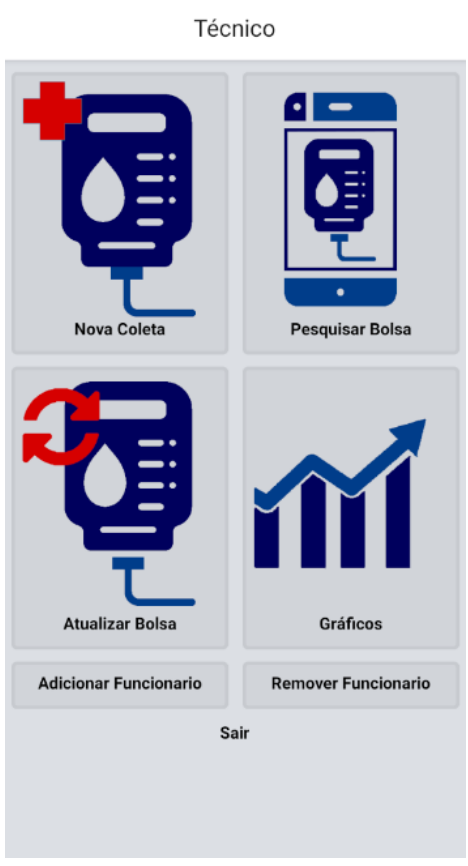

Figura 1. Tela inicial do Hemodata. 